\title{
Deafness, a Social Stigma: Physician Perspective
}

\author{
M. K. Taneja
}

Received: 9 September 2014 / Accepted: 11 September 2014/Published online: 23 September 2014

(C) Association of Otolaryngologists of India 2014

\begin{abstract}
Hearing is an essential sensory sense of an individual for development of speech which is crucial for verbal communication and personality development. It is the second most common form of disability after loco motor disability in India. Disabling hearing loss is more than $40 \mathrm{~dB}$ hearing loss in better ear in a person more than 15 years of age and greater than $30 \mathrm{~dB}$ hearing loss in better hearing ear below 14 years of age. WHO estimated 360 million individuals in the world with disabling hearing loss, out of which $91 \%$ are adults and only $9 \%$ are children. Early and accurate identification of birth asphyxia, hyperbilirubinemia, auditory neuropathy Presbyacusis and avoiding noise pollution and discouraging use of mobile phone, tobacco chewing/smoking, in those who are prone to deafness, an intervention is a must to decrease deafness from our society. Deafness prevention can only be possible with mutual cooperation with dedication of different medical and non-medical personnel and also by helping the persons with deafness. We have to focus not only on the children but also on senior citizens as most alarming, up to $40 \%$, incidence of deafness is in senior citizens above the age of 75 years. Timely cure and preventive measures are essential for better socio-economic state of the country. By helping the persons with deafness, we will not only be doing a great service to the Nation but also to the society at large.
\end{abstract}

Keywords Deafness - Presbyacusis - Neonatal Jaundice . Birth asphyxia $\cdot$ Hyperbilirubinemia .

Auditory neuropathy $\cdot$ Incidence $\cdot$ Noise pollution .

National Deafness Programme $\cdot$ NPPCD $\cdot$ RBSK

M. K. Taneja $(\varangle)$

E-982 C.R. Park, New Delhi, India

e-mail: ijo_editor@rediffmail.com
Hearing is an essential sensory sense of an individual for development of speechwhich is crucial for verbal communication and personality development. Hearing impairment is one of the most frequent sensory deficits in human beings. It is the second most common form of disability after loco motor disability in India [1]. Deafness is like any other human deficiency like blindness, orthopedic problems or any other kind of deficiency/physical challenge. Hence it must not be considered as a social stigma and it needs to be treated at par with other disabilities/physical challenge. Government has social obligation to do whatever is feasible to control and prevent deafness and give similar facilities/privileges to people suffering from any disability/physical challenge.

Disabling hearing loss is more than $40 \mathrm{~dB}$ hearing loss in better ear in a person more than 15 years of age and greater than $30 \mathrm{~dB}$ hearing loss in better hearing ear below 14 years of age.

WHO estimated 360 million individuals in the world with disabling hearing loss, out of which $91 \%$ are adults and only $9 \%$ are children [2].

Prevalence of disabling hearing impairment in South East Asia in children is $2.4 \%$, and adults below 65 years are $9.5 \%$. The prevalence of deafness is as high as $48 \%$ in population above the age of 65 [3].

The prevalence of hearing loss in children has inverse relation with parents' literacy. Amongst adults, only $20 \%$ would benefit from hearing aid and use hearing aid. National Institute on Deafness and Other Communication Disorders (NIDCD) estimates that $15 \%$ of population has got decreased hearing due to loud noise which may be noise at work, leisure activity or use of mobile phone only [4]. Two publications in Indian Journal of Otology suggest that use of mobile phone may lead to sensorineural deafness [5] and if use is more than $30 \mathrm{~min}$, may lead to $10 \mathrm{~dB}$ transient hearing loss [6]. 
As per http://www.nidcd.nih.gov health information statistics and epidemiology, apart from diabetes, high cholesterol and hypertension, smoking, noise pollution and high body mass index factors are the predisposing or precipitating factors for decreased hearing [4].

Although deafness is a global phenomenon, available data indicate that on an average, $6.3 \%$ of the Indian population suffers from hearing loss, which ranges from $4.0 \%$ in urban to $11.0 \%$ in rural and slum areas [7]. Hence apart from Government, we, the physicians have got a moral as well as social duty to dedicate ourselves and work for prevention and control (cure) of deafness. There is a need to identify the possible cause of deafness as well as measures which can be taken to control/prevent/minimize or eradicate this physical deficiency to the extent clinically feasible.

The deafness can be classified into two types-conductive $(50 \%)$ and sensorineural $(50 \%)$. Conductive hearing loss is a mechanical defect in conduction from pinna, external auditory canal, tympanic membrane, middle ear (ossicles, fluid) up to annular ligament at stapedial footplate (otosclerosis). Sensorineural hearing loss is most commonly due to the involvement of sensory hair cells of the cochlea or sometimes of the auditory nerve or processing center in the brain. About $50 \%$ of the patients with sensorineural deafness are congenitally deaf, and $30 \%$ of these congenitally deaf patients have syndromic deafness. Hearing loss is generally described as mild, moderate, severe, or profound. It can be congenital or acquired; prelingual or postlingual. Generally, only children whose hearing loss is greater than 90 decibels $(\mathrm{dB})$ are considered deaf.

Hearing impairment may also be caused by problems during pregnancy and childbirth. These include:

1. Premature birth;

2. Conditions during birth in which a baby lacks enough oxygen to breathe;

3. Rubella, syphilis or certain other infections in a woman during pregnancy;

4. Inappropriate and irrational use of ototoxic drugs during pregnancy and early childhood;

5. Jaundice

\section{Family History}

If both mother and father are affected, the incidence of deafness in their offspring increases $[8,9]$. Consanguinity may be an additional factor in certain communities which can be highlighted and avoided by visuals/publicity. In case of familial deafness option of preimplantation genetic diagnosis should be explained and Government should support to prevent/reduce incidence of deafness in India $[10,11]$.

\section{TORCH Infection}

If the pregnant mother gets an infection (bacterial, viral or rarely parasitic) during pregnancy, it may be transmitted to the fetus.

TORCH comprises of Toxoplasmosis, Others (Chlamydia, HIV, Coxsackie virus, Varicella virus and Syphilis), Rubella, Cytomegalovirus, and Herpes simplex virus.

Symptoms like fever, poor feeding, low birth weight, petechial rash on skin, jaundice with hepatosplenomegaly may be alarming in a baby. TORCH may lead to hearing problem, mental retardation and autism. Diagnosis is by increased IgM against the pathogen.

\section{Birth Asphyxia}

When baby does not receive sufficient oxygen before, during and after birth it may lead to birth asphyxia. Commonest reason is compression of neck by umbilical cord or compression of umbilical cord; exhaustion of mother during anesthesia or low blood pressure leading to poor oxygen saturation of mother, inadequate relaxation of uterus, aspiration and congenital heart or lung disease are other causes of birth asphyxia, which may result in deafness.

\section{Neonatal Jaundice (Hyperbilirubinemia)}

It is the yellowish discoloration of skin and tissues of the new born baby having a bilirubin level more than $85 \mu \mathrm{mol} /$ $1(5 \mathrm{mg} / \mathrm{dl})$. This jaundice is usually physiological which is due to breakdown of fetal haemoglobin and inability of immature hepatic system to cope with it.

The jaundice can be confirmed by blenching the skin by digital pressure. If the jaundice exceeds more than $19.5 \mathrm{mg} / \mathrm{dl}$ (hyperbilirubinemia), the palm and sole become yellowish. It may affects the hearing and neurological process.

Breast feeding protects from jaundice but prematurity, low birth weight, asphysia, TORCH infection, swallowing of blood in caesarian section, polycythemia, delayed umbilical cord clamping, and maternal sepsis and diabetes ameliorates the condition.

\section{Auditory Neuropathy}

It is a hearing disorder where the sound is grasped normally by inner ear but the signal transmission to the brain is impaired. There is extremely poor speech discrimination. Parents initially feel that child can hear but speech development is delayed and child does not respond to commands 
and is careless. The defect is in the cochlea where outer hair cells are normal but inner hair cells are deficient. By virtue of normal outer hair cells cochlear microphonic response (Echogy) and otoacoustic emission (OAEs) is present but acoustic reflex and ABR (Paradoxical ABR) are abnormal or absent. Audiogram may be normal or may be having profound deafness.

The site of lesion is in inner hair cells or synopsis, spiral ganglion. The commonest reason for auditory neuropathy is again anoxia, hyperbilirubinemia, infectious diseases (mumps) and immune disorders.

\section{Nutritional Deficiency}

Deficiency of iron, Vit D [12] folic acid affects the baby leading to poor physical and mental development along with overall age retardation. Gestational development may be hampered due to nutritional deficiency. This issue can be taken up by visual publicity mentioning deficiencies resulting into deafness apart from poor intellect and speech development. Nutritional deficiency may aggravate the prenatal and postnatal infections. Prenatal period is from 22nd week to 7 days after pregnancy.

Classification and diagnosis of various types of deafness is a vast topic hence this article focus only on "How to decrease the incidence of deafness" [13].

\section{Deafness Prevention}

Deafness prevention can only be possible with mutual cooperation of social organizations viz. "Bharat Vikas Parishad" etc. and involvement of NGOs viz. "Lions/ Rotary Club" along with dedication of different medical personnel (i.e., ENT surgeon, Pediatrician, Gynecologist, Audiologist, Speech pathologist, nurses, midwifes, etc.), school teachers, village Sarpanch, by spreading awareness regarding causes of deafness, their diagnosis and treatment.

- Public at large should be awakened by spreading awareness regarding preventable causes of deafness.

- There should be compulsory newborn screening (by OAE/BERA) at birth in the hospital. Toddlers and preschoolers are referred if:

- show developmental delay

- have hereditary disposition for hearing loss

- develop disease or disorder that affects the auditory mechanism.

- All children to be screened and evaluated routinely in kindergarten, and 1st-3rd grades, and 7th and 11th grades by class teachers. The class teachers should be taught in nursery teacher in training (NTT): how to do preliminary free field hearing test?

Tympanometry being automatic, evaluation prevents error of judgment and may be more useful in winters when incidence of deafness is more in children below the age of 8 years $[14,15]$.

- Periodical audiological screening to identify hearing impairment and deafness among high risk population.

- All paramedical staff, pediatrician, gynecologists etc. should be made aware of behavioral enforcement audiometry and its chart should be displayed in all public places [16] (Fig. 1).

- Public must be made aware about the rules regarding noise level in and around schools and hospitals and in factories and an awareness programme should be launched. Residential Welfare Associations [17, 18] (RWA) should be aware of permissible noise level to prevent noise induced hearing loss. RWA should also be awakened about the side effects of fire crackers on festivals [19].

- Strict ban on ototoxic ear drops combinations which are rampant in the market.

- There should be regular advanced learning courses, by Government, for ENT surgeons (both government and private practitioners) and courses should be supported by $\mathrm{MCI} /$ Government.

- Cochlear implant (CI) training program, for government and private ENT practitioners both, according to their competence. CI should be provided through government to break monopoly and malpractices.

- Competent ENT practitioners should get special aids from government for instruments purchase, hospital set up, attending courses abroad so that there should not be malpractices to earn that hugely invested money early.

- There should be research activities, funded by government, related to tinnitus, vertigo, noise-induced deafness, malformed pinna related deafness, congenital deafness, deafness in syndromes, etc.

- There should be mutual knowledge transfer at International level by sending/accepting ENT surgeons for learning, funded by government.

- There should be awards and extended support from the government to those NGOs and Public workers, PHC, CHC and private ENT surgeons who are doing good work in deafness prevention and management.

Association of Otolaryngologist of India (AOI) executive meeting held in the chairmanship of President Dr. Sudhakar Vaidya and National Coordinator Dr. M.K. Taneja came out with the following suggestions:

- Audiometry screening to be taught to all medical/ paramedical staff and all paramedical courses should 
Fig. 1 Behavioral free field age related hearing response

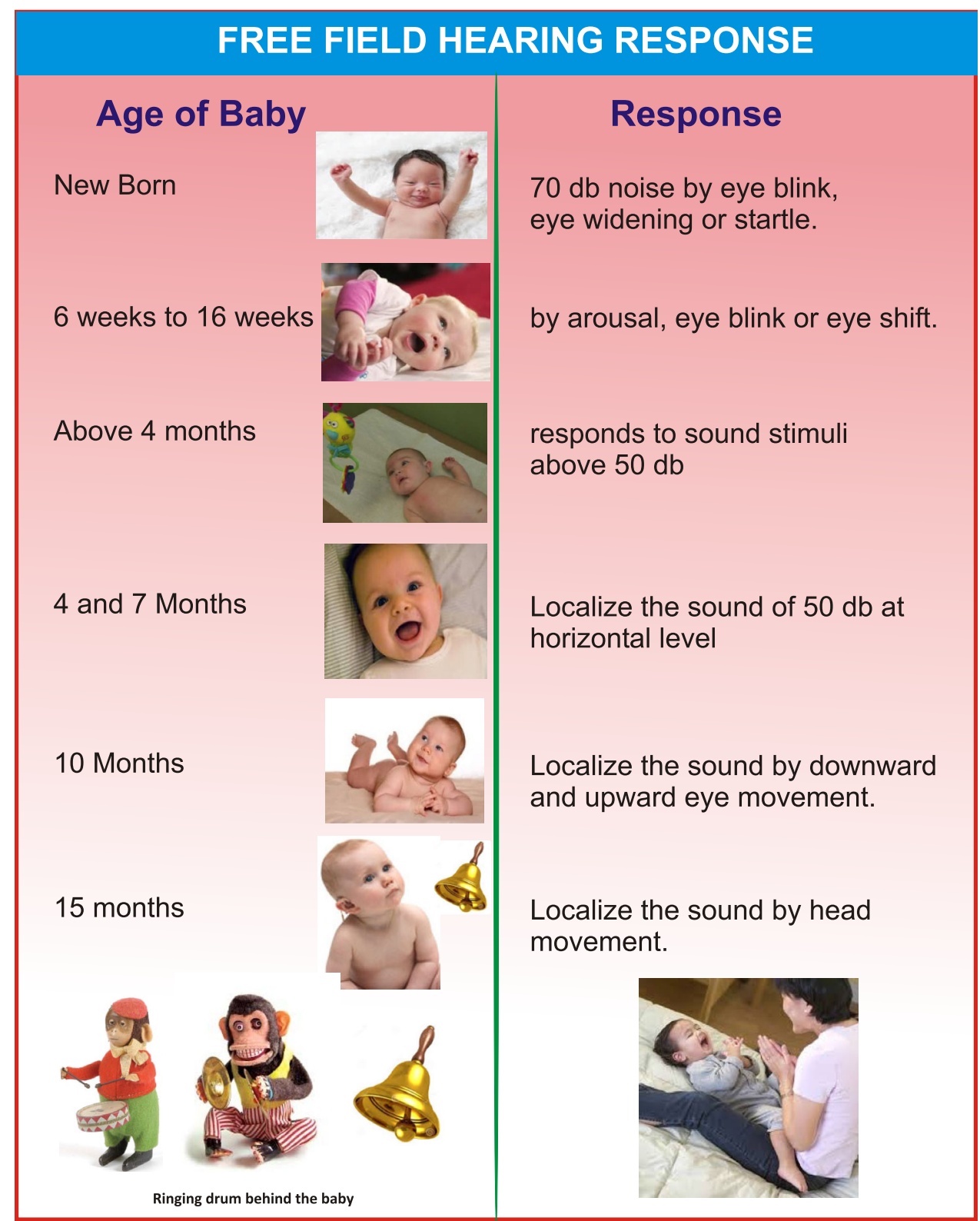

have three full days basic training to evaluate a child or a person for deafness.

- Audiologist/speech therapist certificate course of 6 weeks should be started with the support of Ministry of Labour to cope up with vast deficit of graduate audiologists who intend to work in metro cities only.

- All 50 years onward employees should be screened and made aware of incidence of deafness and preventive measure.

- The budget should be increased at par with eye relief (blindness), National tuberculosis eradication programme.

- Post-MBBS diploma and degree courses in audiology and speech therapy should be started in all medical colleges.
- Though audiology is an essential part of M.S. (ENT) but MCI may be requested to fix up a specific percentage in qualifying examination

- Public at large should be made aware that immunization in children for measles, meningitis, rubella and mumps and in adolescent girls and reproductive females for rubella prevents deafness simultaneously treating the women for TORCH.

- Drivers from sub-urban area should be taught during the licensing programme to avoid blowing pressure horns especially on red lights which is even more harmful to them (drivers).

- Hearing aid is in scarcity: its availability and services for fitting a suitable hearing aid or mould should be a part of national programme. 
- Government agencies should start building partnership with the help of WHO to provide affordable hearing aids and its services

\section{Rashtriya Bal Swasthya Karyakram (RBSK)}

Rashtriya Bal Swasthya Karyakram (RBSK) is an Indian Government's new initiative aimed at screening children from 0 to 18 years for four Ds-Defects at birth, Diseases, Deficiencies and Development Delays including Disabilities. Children diagnosed with illnesses shall receive follow up including surgeries at tertiary level, free of cost under National Rural Health Mission (NRHM). In the long run this programme will help us in protecting and promoting the health of our children. Child Health Screening and Early Intervention Services also aims at reducing the extent of disability, at improving the quality of life and enabling all persons to achieve their full potential. Though by virtue of project children will be screened for hearing disability but by imparting preliminary audiologist training to the field task force, NPPCD enforcement will be much better rather make it successful.

\section{Deafness Treatment}

ENT surgeons can decrease the load of deaf population by treating most of the causes of Conductive deafness through surgery e.g., tympanoplasty, mastoidectomy and ossiculoplasty, Stapedotomy, and middle ear implants. Sensorineural deafness can be taken care of by providing immediate medical treatment [20] or later by hearing aids, BAHA, Cochlear implantation and most recently Brainstem and Midbrain electrode implantation. All this needs dedication, devotion and practice.

\section{Life-Style Changes}

Man is born with inbuilt power to correct many of the body defects and fight illness. Most illnesses start in our minds and grow when abetted by fertilizer viz. depression, tobacco, alcohol, wrong food habits, environmental pollution and modulated by genes. Depression, hostility and anger are the key factors regarding the fighting (immunity) power which is further aggravated by questionable drugs. There is a myth that presbyacusis is genetic also. Gene alone cannot bring on any disease. Presence of a gene only indicates possibility. As human mind is the driving force for wellness as well for illness; hence psychotherapy, yoga, good psychosocial and physical environment along with healthy diet and life style not only prevent but can lead to easy cure of deafness and their better rehabilitation. Extended use of mobile phone should be strictly discouraged in persons with family history of deafness [21].

\section{Conclusion}

Deafness and hearing impairment is the second commonest form of disability after loco motor disability in India. Early and accurate identification with timely intervention is a must to decrease deafness from our society. Deafness prevention can only be possible with mutual cooperation with dedication of different medical and non-medical personnel and also by helping the persons with deafness. We have to focus not only on the children but also on senior citizens as most alarming, up to $40 \%$, incidence of deafness is in senior citizens. Timely cure and preventive measures are essential for better socio-economic state of the country. By helping the persons with deafness, we will not only be doing a great service to the Nation but also earn satisfaction, self-respect, and an honorable status in the society. Remember that we are just taking a few steps forward and which will translate into miles of travel to reach the destination.

\section{References}

1. Taneja MK (2012) Role of ENT surgeons in the national program for prevention and control of deafness. Indian J Otol 18:119-121

2. World Health Organization deafness and hearing impairment fact sheet February 2014. http://www.who.int/mediacentre/factsheet/ fs $300 /$ index

3. WHO global estimates on prevalence of hearing loss 2012. www.who.int/pbd/deafness/WHO_GE_HL.pdf

4. Health InfoStatistics and Epidemiology. Quick statistics, National Institute on Deafness and Other Communication Disorders (NIDCD). http://www.nidcd.nih.gov/health/statistics/pages/quick. aspx

5. Sahoo GC, Sebastian H (2011) Prevalence of sensorineural deafness in habitual mobile phone users. Indian J Otol 17:97-100

6. Ramya CS, Karthiyanee K, Vinutha S (2011) Effect of mobile phone usage on hearing threshold: a pilot study. Indian J Otol 17: 159-161

7. National Program for prevention and control of deafness (NPPCD) operational Guideline. http://mohfw.nic.in

8. Focus on NIDCD: research in Pakistan yields findings on hereditary hearing loss, May/June 2014 vol 13, issue 3

9. Zakzouk SM (2000) Impact of consanguinity on childhood hearing impairment. Indian J Otol 6:67-70

10. Taneja MK (2012) Preimplantation genetic diagnosis and deafness. Indian J Otolaryngol Head Neck Surg 64(2):103-105

11. Taneja MK (2014) Preimplantation genetic diagnosis: its role in prevention of deafness. Indian J Otolaryngol Head Neck Surg 66(1):1-3

12. Taneja MK (2012) Role of vitamin D in prevention of deafness. Indian J Otol 18:55-57 
13. Taneja MK, Taneja V (2013) Vitamin D deficiency in E.N.T. patients. Indian J Otolaryngol Head Neck Surg 65(1):57-60

14. Taneja MK (2001) Tympanometry in school children. Indian J Otol 7:139-141

15. Taneja MK (2003) Secretary otitis media: its seasonal variation. Indian J Otol 9:5-8

16. Taneja MK (2012) National deafness program and behavioral enforcement audiometry. Indian J Otol 18:1-2

17. Taneja MK (2004) Noise pollution and civil laws. Indian J Otol 10:3-6
18. Noise pollution (repulation and control) rules, India 2000(modified) up to.... Under the environment protection act 1986. http://envfor.nic.in/division/environment-protection

19. Taneja MK (2004) Diwali-fire crackers and deafness. Indian J Otol 10:3-5

20. Taneja MK (2010) Sudden sensorineural deafness. Indian J Otol 16:3-7

21. Hegde MC, Shenoy VS, Kamath PM, Rao RA, Prasad V, Varghese BS (2013) Mobile phones: its effect on hearing. Indian J Otol 19:122-126 